\title{
The Clinical Outcomes of Hemicortical Extracorporeal Irradiated Autologous Bone Graft After Tumor Resection of Bone and Soft Tissue Sarcoma
}

\author{
TOMOKI NAKAMURA ${ }^{1}$, TOMOHIRO FUJIWARA ${ }^{2}$, YUSUKE TSUDA $^{2}$, ADESEGUN ABUDU $^{2}$, \\ YOSHIHITO NOMOTO ${ }^{3}$, AKINORI TAKADA $^{3}$, YUTAKA TOYOMASU $^{3}$, \\ TOMOHITO HAGI ${ }^{1}$, KUNIHIRO ASANUMA ${ }^{1}$ and AKIHIRO SUDO ${ }^{1}$ \\ ${ }^{1}$ Department of Orthopaedic Surgery, Mie University Graduate School of Medicine, Tsu, Japan; \\ ${ }^{2}$ Oncology Service, The Royal Orthopaedic Hospital, Birmingham, U.K.; \\ ${ }^{3}$ Department of Radiology, Mie University Graduate School of Medicine, Tsu, Japan
}

\begin{abstract}
Background/Aim: We analyzed the process of healing at osteotomy sites and timing of achievement of full weight-bearing in sarcoma patients who underwent hemicortical or intercalary reconstruction using the extracorporeal irradiated autologous bone graft technique. Patients and Methods: We studied 10 patients who had undergone tumor resection and reconstruction with hemicortical extracorporeal irradiated autologous bone graft at mid-shaft femur or tibia. The control group consisted of 30 patients who received the reconstruction using intercalary bone graft. Results: Full weight-bearing was achieved in all 10 patients at a median time of 4.8 months. Function was excellent in all patients. When comparing the clinical outcome among the patients who received intercalary and hemicortical grafts, the duration to full weight-bearing achievement in patients who received hemicortical graft was shorter than that in those with intercalary graft. Conclusion: Early full weight-bearing may be achieved in patients undergoing hemicortical resection and reconstruction using extracorporeal irradiated autologous bone graft.
\end{abstract}

Intraoperative extracorporeal irradiation and re-implantation for bone sarcomas was first described by Spira and Lubin in 1968 (1). This technique enables biological reconstruction with a precise fit, helps restore function, and prevents long-

This article is freely accessible online.

Correspondence to: Tomoki Nakamura, Department of Orthopaedic Surgery, Mie University Graduate School of Medicine. 2-174 Edobashi, Tsu, Mie, 514-8507, Japan. Tel: +81 592315022, Fax: +81 592315211, e-mail: tomoki66@clin.medic.mie-u.ac.jp

Key Words: Extracorporeal irradiation, autologous bone graft, hemicortical, sarcoma, weight-bearing. term complications of endoprosthetic replacement, such as loosening and breakage (2-4). However, non-union in intercalary reconstructions using extracorporeal irradiated autologous bone grafts with vascularized fibular grafts has been reported to occur in $7-31 \%$ of all patients (5-7). In contrast, hemicortical resection and reconstruction using allograft or autograft for selected bone and soft tissue malignant tumors yield excellent oncologic and functional outcomes (8-11). Hemicortical resection may be also indicated for a soft tissue sarcoma (STS) attached to the surface of the bone. We applied hemicortical resection and reconstruction using extracorporeal irradiated autologous bone graft after tumor resection for selected patients with bone and soft tissue sarcoma. Surprisingly, only a few cases have been reported on hemicortical resection and reconstruction using extracorporeal irradiated autologous bone graft $(11,12)$. In the present study, we described clinical results obtained using this procedure. Furthermore, we hypothesized that the healing process at osteotomy sites and the duration to full weight-bearing from surgery in patients who underwent hemicortical reconstruction may be shorter than that in those with intercalary reconstruction, because of the need for a wider area for attachment of extracorporeal irradiated autologous bone when performing hemicortical reconstruction. Therefore, we compared the process of healing at osteotomy sites and timing of achievement of full weight-bearing between patients who underwent hemicortical reconstruction and those who underwent intercalary reconstruction using extracorporeal irradiated autologous bone graft technique.

\section{Materials and Methods}

We studied 10 consecutive patients who had undergone limb-sparing tumor resection and reconstruction with hemicortical extracorporeal irradiated autologous bone graft for a bone sarcoma and STS of the 
mid-shaft femur or tibia at Mie University Hospital between 2009 and 2016 (Table I). Histological diagnosis was obtained for all patients. One patient had periosteal osteosarcoma and nine had STS. Three patients received combined neo-adjuvant and adjuvant chemotherapy, and another patient received adjuvant chemotherapy alone. Clinical and radiological records of the patients were reviewed retrospectively. The bone was divided at least $2 \mathrm{~cm}$ distally and proximally from the tumor margin, as assessed on magnetic resonance imaging scans at the time of initial presentation. Percent of cortical circumstance of the resected bone was measured using computed tomography after surgery. After excision of the bone and tumor, the soft tissue part of the tumor was removed from the bone and sent for histological examination, with the bone available for extracorporeal sterilization. The bone was wrapped in vancomycin antibiotic-soaked gauze and placed in two sterile bags before being sent to the radiotherapy suite in a special box. A dose of $70 \mathrm{~Gy}$ of radiotherapy was used for sterilization. A single irradiation of $70 \mathrm{~Gy}$ was performed to sterilize.The bone was then re-implanted and fixed with suitable plate and/or screws osteosynthesis. A single plate was used in seven patients but not in the remaining three due to the potential difficulty of soft tissue coverage if the plate was used. We allowed partial weight-bearing at 1 month after adequate internal plate fixation. The control group consisted of 30 patients who were diagnosed with bone sarcoma of the mid-shaft femur or tibia between 2000 and 2016 at Mie University Hospital and the Royal Orthopaedic Hospital. They received intercalary resection including tumor and reconstruction using intercalary extracorporeal irradiated autologous bone graft. The procedure of resection and irradiation of the bone was similar. The mean length of the resected bone was $13.8 \mathrm{~cm}$. A dose of 70 or 90 Gy of radiotherapy was used for sterilization. In nine patients, the medullary cavity of the bone was then filled with gentamicin containing bone cement to strengthen the bone. We ensured that there was no cement in the last $2 \mathrm{~cm}$ of the bone ends to allow for bony ingrowth at the osteotomy sites. In 21 patients, vascularized fibula graft was used for strengthening the bone. The bone was then re-implanted and fixed with a suitable plate (single plate: 25 patients, double plate: 5 patients). Patient background, age, and administration of neo- and adjuvant chemotherapy were significantly different between groups. However, there was no significant difference in resected bone length between groups.

Complete incorporation was assumed when the whole osteotomy line disappeared on CT. Proximal and distal bone fusion was assumed when osteotomy line disappered on radiograph. Generally, full weight-bearing in patients with intercalary graft was acquired when osteotomy line disappeared on radiograph at proximal and distal osteotomy sites. For the patients with hemicortical graft, full weight-bearing was acquired 3 or 4 months after surgery, if the rigid fixation using plate and screw was performed. The statistical associations between the clinicopathological factors were evaluated using the Mann-Whitney $U$-test for quantitative data, and Fisher exact or X2 test for qualitative data. This study was approved by the institutional review board of our hospital.

\section{Results}

The clinical background of the study patients is shown in Table I. None of the patients had metastases at diagnosis. The mean age of the patients at the time of surgery was 63 years (range $=37-84$ years). Five patients were male and five were female. The mean length of the resected bone was $11.7 \mathrm{~cm}$ (range $=8-15 \mathrm{~cm}$ ). The extent of cortical circumstance of the resected bone varied between $30 \%$ and $50 \%$. The patients had been followed up for a mean of 54 months (range=29-112 months) at the time of the study. Nine patients were alive at the time of our study, but one patient had previously died because of lung metastasis (Table II). Local recurrence in the soft tissue developed in one patient (No. 6), who then received radiotherapy. No patient developed local recurrence in the reimplanted bone. There were no fractures of the graft or of the remaining host bone in this series. One patient (No. 8) developed superficial infection, and debridement was performed; the wound was healed without removal of the implant (Figures 1 and 2). Another patient (No.5) developed compartment syndrome postoperatively, and was first treated with decompressive fasciotomy before additional local flap and skin graft procedures were performed one month later. Primary union of the distal and proximal osteotomy sites was achieved in nine patients at a median postoperative time of 4 months and 7.5 months, respectively. Primary union at the proximal osteotomy site was not achieved in one patient (No. 2) after 31 months post-surgery. Nine grafts were incorporated at a mean of 12.3 months (range $=4-26$ months) after surgery. Full weight-bearing was achieved in all 10 patients at a median and mean time of 4.8 and 5.3 months, respectively (Table II). For the patients who underwent plate fixation, full weight-bearing was achieved at a median and mean time of 3.5 and 3.9 months, respectively. Function was excellent in all patients as they could walk without any support.

When we compared the clinical outcome among the patients who received intercalary and hemicortical grafts, the duration to full weight-bearing achievement in patients who received hemicortical graft was shorter than that in those with intercalary graft (mean: 5.3 months $v s .10 .5$ months, $p=0.049$ ) (Table III). At the proximal osteotomy site, primary bone fusion was achieved in 9 patients in the hemicortical group and 21 patients in the intercalary group. At the distal osteotomy site, primary bone fusion was achieved in 10 patients in the hemicortical group and 23 patients in the intercalary group. Although the duration of fusion achievement at the distal osteotomy site was not different, proximal fusion was achieved earlier in patients who received hemicortical graft than in those who received intercalary graft (mean: 5.7 months in 9 patients vs. 10.2 months in 21 patients, $p=0.04$ ). Finally, at the final follow-up period, primary bone fusion was achieved in 9 patients in the hemicortical group at all circumstances and in 19 patients in the intercalary group at both proximal and distal sites. We also compared the duration until full weight-bearing between the group with chemotherapy and without chemotherapy. There was no difference between the group with chemotherapy (10 months) and without chemotherapy ( 7 months, $p=0.62$ ). Furthermore, there was also no significant difference in the proximal 
Table I. Clinical characteristics in patients who received hemicortical resection and reconstruction.

\begin{tabular}{|c|c|c|c|c|c|c|}
\hline No. & Age/Gender & Diagnosis & Site & $\begin{array}{l}\text { Resected } \\
\text { bone }(\mathrm{cm})\end{array}$ & $\begin{array}{c}\% \text { of cortical } \\
\text { circumstance resected }\end{array}$ & Fixation \\
\hline 1 & $76 / \mathrm{F}$ & MPNST & Tibia & 8 & $30 \%$ & $\begin{array}{l}\text { Screws } \\
\text { LD flap }\end{array}$ \\
\hline 2 & $37 / F$ & OS & Femur & 8 & $40 \%$ & $\begin{array}{l}\text { Single plate } \\
\text { Screws }\end{array}$ \\
\hline 3 & $39 / F$ & UPS & Tibia & 11 & $50 \%$ & $\begin{array}{l}\text { Screws } \\
\text { LD flap }\end{array}$ \\
\hline 4 & $84 / \mathrm{F}$ & LMS & Tibia & 11 & $40 \%$ & $\begin{array}{l}\text { Single plate } \\
\text { Screws }\end{array}$ \\
\hline 5 & $60 / \mathrm{M}$ & UPS & Tibia & 15 & $40 \%$ & Screws \\
\hline 6 & $68 / \mathrm{M}$ & SS & Tibia & 8.5 & $30 \%$ & $\begin{array}{l}\text { Single plate } \\
\text { Screws }\end{array}$ \\
\hline 7 & $71 / \mathrm{M}$ & De-dif LPS & Femur & 15 & $30 \%$ & $\begin{array}{l}\text { Single plate } \\
\text { Screws }\end{array}$ \\
\hline 8 & $67 / F$ & SS & Femur & 12 & $30 \%$ & $\begin{array}{l}\text { Single plate } \\
\text { Screws }\end{array}$ \\
\hline 9 & $58 / \mathrm{M}$ & MyxoidLPS & Femur & 13 & $40 \%$ & $\begin{array}{l}\text { Single plate } \\
\text { Screws }\end{array}$ \\
\hline 10 & $69 / \mathrm{M}$ & De-dif LPS & Femur & 15 & $50 \%$ & $\begin{array}{l}\text { Single plate } \\
\text { Screws }\end{array}$ \\
\hline
\end{tabular}

MPNST: Malignant peripheral nerve sheath tumor; OS: osteosarcoma; UPS: Undifferentiated pleomorphic sarcoma; LMS: leiomyosarcoma; SS: synovial sarcoma; de-dif LPS: de-differentiated liposarcoma; LD flap: Latissimus dorsi flap.

Table II. Clinical outcome of 10 patients with hemicortical reconstruction.

\begin{tabular}{|c|c|c|c|c|c|c|c|}
\hline \multirow[t]{2}{*}{ No. } & \multirow[t]{2}{*}{ Age/Gender } & \multicolumn{2}{|c|}{ Fusion (months) } & \multirow[t]{2}{*}{ Complications } & \multirow{2}{*}{$\begin{array}{c}\text { FWB } \\
\text { (months) }\end{array}$} & \multirow{2}{*}{$\begin{array}{c}\text { Follow-up } \\
\text { (months) }\end{array}$} & \multirow[t]{2}{*}{ Status } \\
\hline & & proximal & distal & & & & \\
\hline 1 & $76 / \mathrm{F}$ & 4 & 6 & & 6.2 & 84 & $\mathrm{CDF}$ \\
\hline 2 & $37 / F$ & $\mathrm{n}$ & 4 & & 3.5 & 31 & $\mathrm{CDF}$ \\
\hline 3 & $39 / \mathrm{F}$ & 2 & 21 & & 10.3 & 112 & AWD \\
\hline 4 & $84 / \mathrm{F}$ & 5 & 26 & & 2.0 & 26 & AWD \\
\hline 5 & $60 / \mathrm{M}$ & 9 & 9 & Compartment syndrome & 9.2 & 57 & $\mathrm{CDF}$ \\
\hline 6 & $68 / \mathrm{M}$ & 4 & 4 & Local recurrence & 4.0 & 40 & DOD \\
\hline 7 & $71 / \mathrm{M}$ & 5.5 & 2 & & 5.5 & 69 & NED \\
\hline 8 & $67 / \mathrm{F}$ & 4 & 11 & Infection & 3.3 & 35 & NED \\
\hline 9 & $58 / \mathrm{M}$ & 14 & 4.5 & & 6.1 & 55 & $\mathrm{CDF}$ \\
\hline 10 & $69 / \mathrm{M}$ & 4 & 14 & & 3.0 & 29 & NED \\
\hline
\end{tabular}

FWB: Full weight-bearing; CDF: continuous disease-free; NED: No evidence of disease; AWD: alive with disease; DOD: died of disease.

( $p=0.53)$ and distal bone fusion $(p=0.82)$ between the group with chemotherapy and without chemotherapy.

\section{Discussion}

Our results of 10 hemicortical procedures for bone and STS showed good oncological and functional outcomes. No extracorporeal irradiated autologous bone graft complications occurred, and there were no fractures of the remaining hemicortex bone. All patients could walk without any support and obtained full weight-bearing walking at a median time of 4.8 months. More than six months were necessary for three patients without plate fixation to achieve full weight-bearing walking due to prevention of the fracture. The duration to achievement of full weight-bearing walking in patients who received hemicortical graft was shorter than that in those who received intercalary graft. Although the exact time of incorporation was difficult, we allowed partial weight-bearing at 1 month after adequate internal plate fixation and full weight-bearing at median and mean times of 4.8 and 5.4 

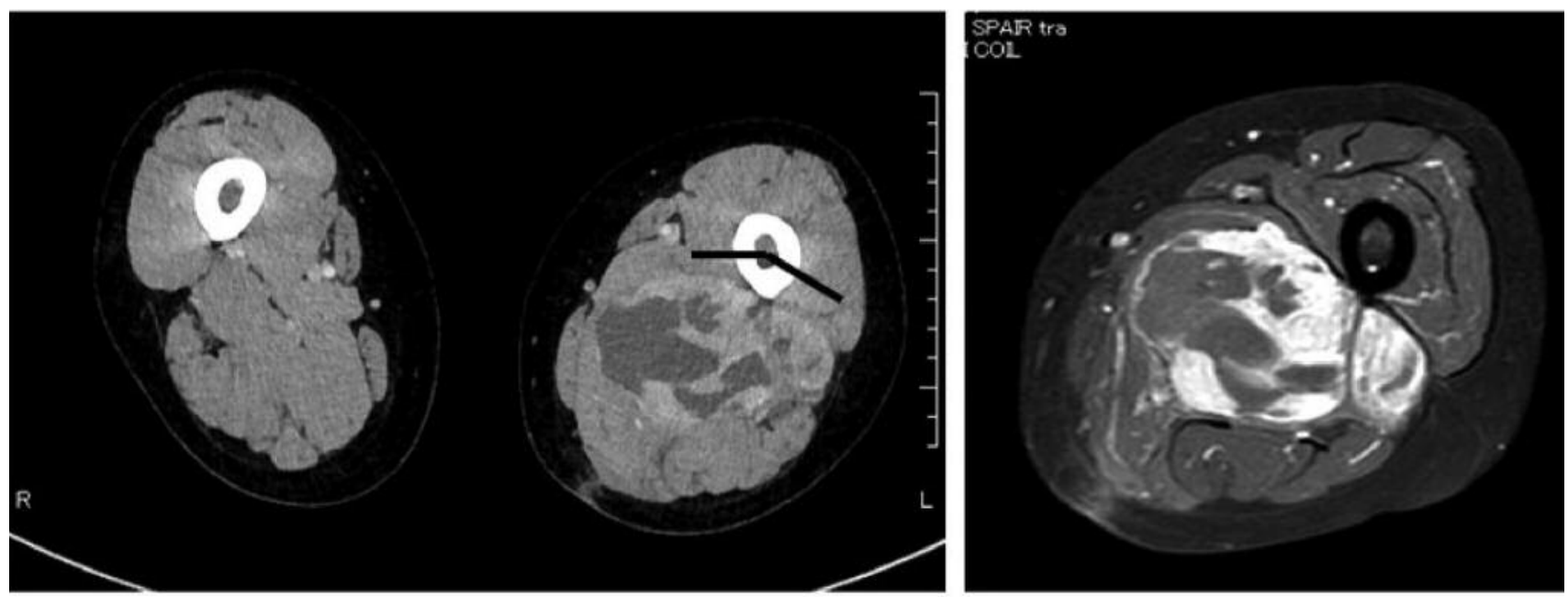

Figure 1. Contrast-enhanced computed tomography (CT) (left) and magnetic resonance imaging (right) showing synovial sarcoma of the left thigh (Case 8). The arrow on the CT represents the cutting line.

months, respectively. No fractures of the extracorporeal irradiated autologous bone and host hemicortex occurred. Although hemicortical reconstruction using extracorporeal irradiation and re-implantation has not been reported in a caseseries, hemicortical reconstruction using allograft, fibula graft, and pasteurized autograft has previously been reported (8-10, $13,14)$. The most frequent complication in this study was host bone fracture, with a reported rate of $15 \%$ to $27 \%$ in previous studies that evaluated more than 10 patients $(8-10,13)$. First, perfect fitting of the allograft may reduce fracture rate $(8,15)$. Contrary to the allograft, it is relatively easy to obtain perfect cortical apposition between the irradiated autologous bone and host cortices at the junction. Second, the preserved cancellous and cortical bone on the other side of the involved long bone could provide a wider contact area for autograft incorporation, maintain mechanical support, and prevent fracture $(8,16,17)$. Finally, appropriate reinforcement is necessary for the prevention of fracture. Bus et al. have suggested strategies of hemicortical allograft fixation according to the extent of cortical resection and resected bone lengths (8). The authors have recommended plate fixation when the resected bone is $>8 \mathrm{~cm}$ and in $25 \%$ to $50 \%$ of cortical circumstance, as was the case in the present study (8). Screw fixation was performed in three patients because of the difficulty of soft tissue coverage if the plate was used. For these patients, full weight-bearing was allowed after 6 months because we confirmed sufficient union to allow partial and full weight-bearing carefully.

Non-union in intercalary reconstructions with extracorporeal irradiated autologous bone grafts with vascularized fibular grafts has been reported to occur in between $7 \%$ and $31 \%$ of patients (5-7). In the present study, proximal fusion alone was achieved earlier in patients who received hemicortical graft
Table III. Comparison between the patients with hemicortical and intercalary resection and graft.

\begin{tabular}{|c|c|c|c|}
\hline Variables & Intercalary & Hemicortical & $p$-Value \\
\hline \multicolumn{4}{|l|}{ Age } \\
\hline mean (years) & 17 & 63 & $<0.0001$ \\
\hline \multicolumn{4}{|l|}{ Gender } \\
\hline Male (n) & 20 & 5 & \multirow[t]{2}{*}{0.35} \\
\hline Female (n) & 10 & 5 & \\
\hline \multicolumn{4}{|c|}{ Resected bone chemotherapy } \\
\hline $\begin{array}{l}\text { Mean } \\
(\mathrm{cm})\end{array}$ & 13.8 & 11.7 & 0.51 \\
\hline Yes (n) & 26 & 4 & \multirow[t]{2}{*}{0.0007} \\
\hline No $(n)$ & 4 & 6 & \\
\hline \multicolumn{4}{|c|}{ Fusion at proximal site } \\
\hline Yes (n) & 21 & 9 & \multirow[t]{2}{*}{0.4} \\
\hline No (n) & 9 & 1 & \\
\hline mean (months) & 10.2 & 5.7 & 0.04 \\
\hline \multicolumn{4}{|c|}{ Fusion at distal site } \\
\hline Yes (n) & 23 & 10 & \multirow[t]{2}{*}{0.22} \\
\hline No (n) & 7 & 0 & \\
\hline mean (months) & 7.3 & 10.8 & 0.53 \\
\hline \multicolumn{4}{|c|}{ Primary fusion at both sites } \\
\hline Yes & 19 & 9 & \multirow[t]{2}{*}{0.23} \\
\hline No & 11 & 1 & \\
\hline \multicolumn{4}{|c|}{ Duration between surgery and FWB } \\
\hline Mean (months) & 10.5 & 5.3 & 0.049 \\
\hline
\end{tabular}

FWB: Full weight-bearing.

than in those who received intercalary graft. Nine grafts were completely incorporated at a mean of 12.3 months after surgery. Liu et al., in a study including 13 patients who received hemicortical resection and reconstruction using 

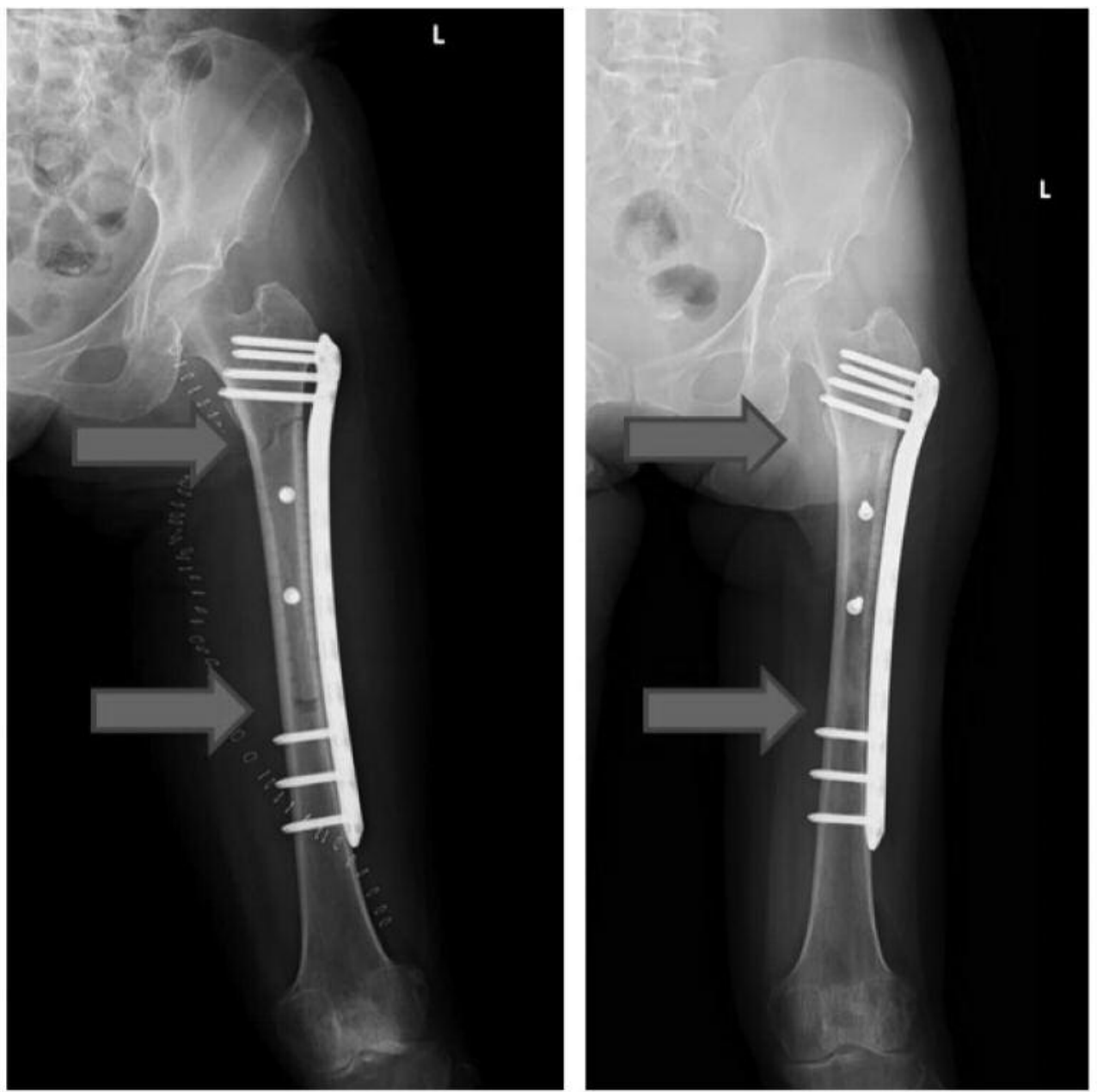

Figure 2. Images showing the post-operative radiograph (Case 8). Arrows show the osteotomy sites. After 11 months, there is sound incorporation of the autograft (left: 1 week after surgery; right: 11 months after surgery).

pasturised autograft for parosteal osteosarcoma of the distal femur, have reported that the mean time to union was 11.2 months (13). Although there has been no report concerning bone fusion and hemicortical autograft when using the liquid nitrogen method, there may be no differences in duration until complete bone union depending on bone graft recycling methods.

Full weight-bearing was achieved in all 10 patients at median and mean times of 4.8 and 5.3 months, respectively. Moreover, patients who underwent plate fixation achieved full weight-bearing at median and mean times of 3.5 and 3.9 months, respectively. The duration to full weight-bearing achievement in patients who received hemicortical graft was shorter than that in those with intercalary graft. In the present study, the mean and median durations to full weight-bearing achievement in patients who received intercalary graft were 10.5 months and 7 months, respectively. We suggest that early full weight-bearing may be achieved if perfect fitting of autograft and additional reinforcement are performed in patients who received hemicortical autograft, because the preserved cancellous and cortical bone on the remaining bone, reinforced by internal fixation, could provide a wider contact area for autograft incorporation, maintain mechanical support, and prevent fracture even if both proximal and distal bone unions are not completely achieved. We also emphasize that further study is necessary to evaluate the clinical outcome in patients who underwent hemicortical resection $>50 \%$ of cortical circumstance.

Our study has several limitations. First, it is a selective series. Some surgeons may choose adjuvant radiotherapy if safe surgical margin is not acquired. However, if adjuvant radiotherapy is planned, large part of the femur may be included in the field of radiotherapy. Fractures after radiation have been reported in 1.2-9\% of cases (18). Second, the 
number of patients included was small, although there are no reports with a sufficient number of patients treated with hemicortical resection and reconstruction using extracorporeal irradiated autologous bone graft. Third, the long duration until full weight-bearing in patients with intercalary graft may be due to the high rate of patients receiving chemotherapy, although there was no significant difference between the group with and without chemotherapy. The retrospective nature of the study is another limitation. However, we suggest that early full weight-bearing may be achieved in patients undergoing hemicortical resection and reconstruction using extracorporeal irradiated autologous bone graft if the autograft is additionally reinforced.

\section{Conflicts of Interest}

The Authors declare that are no conflicts of interest regarding this study.

\section{Authors' Contributions}

TN designed the study and analyzed the data. TN also wrote and revised the manuscript. TF and YT collected and analyzed the data. AA, KA, HT, YN, AT and YT acquired the data. All Authors were responsible for the treatment of patients. All Authors contributed to the writing of the manuscript. All authors read and approved the final manuscript.

\section{Acknowledgements}

There was no supportive funding in the present study.

\section{References}

1 Spira E and Lubin E: Extracorporeal irradiation of bone tumours: a preliminary report. Israel J Med Sci 4(5): 1015-1019, 1968. PMID: 5251288.

2 Abudu A, Carter SR and Grimer RJ: The outcome and functional results of diaphyseal endoprostheses after tumor resection. J Bone Joint Surg Br 78(4): 652-657, 1996. PMID: 8682837.

3 Ahlmann ER and Menendez LR: Intercalary endoprosthetic reconstruction for diaphyseal bone tumours. J Bone Joint Surg Br 88(11): 1487-1491, 2006. PMID: 17075095. DOI: 10.1302/ 0301-620X.88B11.18038

4 Nakamura T, Abudu A, Grimer RJ, Carter SR, Jeys L and Tillman RM: The clinical outcomes of extracorporeal irradiated and re-implanted cemented autologous bone graft of femoral diaphysis after tumour resection. Int Orthop 37(4): 647-651, 2013. PMID: 23271688. DOI: 10.1007/s00264-012-1715-2

5 Kreig AH, Davidson AW and Stalley PD: Intercalary femoral reconstruction with extracorporeal irradiated autogenous bone graft in limb-salvage surgery. J Bone Joint Surg Br 89(3): 366-371, 2007. PMID: 17356151. DOI: 10.1302/0301-620X.89B 3.18508

6 Chen TH, Chen WM and Huang CK: Reconstruction after intercalary resection of malignant bone tumours. J Bone Joint Surg Br 87(5): 704-709, 2005. PMID: 15855376. DOI: 10.1302/ 0303-620X.87B5.15491
7 Davidson AW, Hong A, SW McCarthy and Stalley PD: En-bloc resection, extracorporeal irradiation, and re-implantation in limb salvage for bony malignancies. J Bone Joint Surg Br 87(6): 851857, 2005. PMID: 15911672. DOI: 10.1302/0301-620X.87 B6.15950

8 Bus MP, Bramer JAM, Schaap GR, Schreuder HW, Jutte PC, van der Geest IC, van de Sande MA and Dijkstra PD: Hemicortical resection and inlay allograft reconstruction for primary bone tumors. J Bone Joint Surg Am 97(9): 738-750, 2015. PMID: 25948521. DOI: 10.2106/JBJS.N.00948

9 Deijkers RL, Bloem RM, Hogendoorn PC, Verlann JJ, Kroon $\mathrm{HM}$ and Taminiau AH: Hemicortical allograft reconstruction after resection of low-grade malignant bone tumours. J Bone Joint Surg Br 84(7): 1009-1014, 2002. PMID: 12358363.

10 Agarwal M, Puri A, Anchan C, Shah M and Jambhekar N: Hemicortical excision for low-grade selected surface sarcomas of bone. Clin Orthop Relat Res 459: 161-166, 2007. PMID: 17415008. DOI: 10.1097/BLO.0b013e318059b8eb

11 Chen WM, Wu PK, Chen CF, Chung LH, Liu CL and Chen TH: High-grade osteosarcoma treated with hemicortical resection and biological reconstruction. J Surg Oncol 105(8): 825-829, 2012. PMID: 22212886. DOI: 10.1002/jso.23005

12 Araki N, Myoui A, Kuratsu S, Hishimoto N, Inoue T, Kudawara I, Ueda T, Yoshikawa H, Masaki N and Uchida A. Intraoperative extracorporeal autogenous irradiated bone grafts in tumor surgery. Clin Orthop Relat Res 368: 196-206, 1999. PMID: 10613169.

13 Liu T, Liu ZY, Zhang Q and Zhang XS: Hemicortical resection and reconstruction using pasteurised autograft for parosteal osteosarcoma of the distal femur. Bone Joint J 95-B(9): 1275-1279, 2013. PMID: 23997145. DOI: 10.1302/0301-620X.95 B9.31433

14 Lenze U, Kasal S, Hefti F and Kreig AH: Non-vascularised fibula grafts for reconstruction of segmental and hemicortical bone defects following meta-/diaphyseal tumour resection at extremities. BMC Musculoskelet Disord 18(1): 289, 2017. PMID: 28679368. DOI: 10.1186/s12891-017-1640-z

15 Aponte-Tiano L, Ritacco LE, Ayerza MA, Luis Muscolo D, Albergi JI and Farfall GL: Does intraopetative navigation assistance improve bone tumor resection and allograft reconstruction results? Clin Orthop Relat Res 473(3): 796-804, 2015. PMID: 24711134. DOI: 10.1007/s11999-014-3604-Z

16 Cascio BM, Thomas KA and Wilson SC: A mechanical comparison and review of transverse step-cut, and sigmoid osteotomies. Clin Orthop Relat Res 411: 296-304, 2003. PMID: 12782888. DOI: 10.1097/01.blo.0000069895.31220.e8

17 Clark CR, Morgan C, Sonstegard DA and Matthews LS: The effect of biopsy-hole shape and size on bone strength. J Bone Joint Surg Am 59(2): 213-217, 1977. PMID: 845207.

18 Seinen JM, Jutte PC, Been LB, Pras E and Hoekstra HJ: Fractures after multimodality treatment of soft tissue sarcoma with isolated limb perfusion and radiotherapy; likely to occure and hard to heal. Eur J Surg Oncol 44(9): 1398-1405, 2018. PMID: 29789188. DOI: 10.1016/j.ejso.2018.04.012.

Received August 22, 2019

Revised September 5, 2019

Accepted September 10, 2019 